\title{
VJestern
}

\section{Closing the Loop on Collections Review}

\author{
By: Kristin Calvert \& Whitney Jordan
}

\begin{abstract}
Resource cancellations happen all the time; however, assessing the outcomes of this process isn't necessarily a priority. As our profession continues to move towards data supported decisions, how can we connect new data to decisions made 2-4 years ago? Western Carolina University will outline their approach to assessing their most recent cancellation decisions using interlibrary loan and historical journal price analysis data and discuss their plans for using key findings to plan for future collections reviews and to make budget asks.
\end{abstract}

Calvert, K., \& Jordan, W. (2020). Closing the Loop on Collections Review. Serials Review, 46(3), 209-214. https://doi.org/10.1080/00987913.2020.1806647

Publisher version of record available at: https://doi.org/10.1080/00987913.2020.1806647.

Archived version from NC DOCKS available at: https://libres.uncg.edu/ir/wcu/listing.aspx?styp=ti\&id=33510. 


\title{
Closing the Loop on Collections Review
}

\author{
Kristin Calvert and Whitney Jordan \\ Western Carolina University \\ Hunter Library \\ 176 Central Dr \\ Cullowhee, NC 28723
}

\begin{abstract}
Author Note
Kristin Calvert, Head of Content Organization \& Management, kcalvert@wcu.edu
\end{abstract}

Whitney Jordan, Acquisitions Librarian, wpjordan@wcu.edu 


\section{Abstract}

Resource cancellations happen all the time; however, assessing the outcomes of this process isn't necessarily a priority. As our profession continues to move towards data supported decisions, how can we connect new data to decisions made 2-4 years ago? Western Carolina University will outline their approach to assessing their most recent cancellation decisions using interlibrary loan and historical journal price analysis data and discuss their plans for using key findings to plan for future collections reviews and to make budget asks. 


\section{Closing the Loop on Collections Review}

\section{Introduction}

Collections and serials review are part of every librarian's reality. They may not happen every year, and some may have larger implications than others, but it's something we all encounter. Often the decisions are made, the cancellations enacted, but the day-to-day demands of the job may take priority over following up on how the review went. The cycle of evaluation typically begins and ends with a decision whether to (re)subscribe. Critically reviewing the process, and whether the outcomes of the assessment were met, is an underdeveloped area of study for collections assessment.

In 2016/17, the librarians at Western Carolina University (WCU) undertook a collection review to address a significant budget shortfall which resulted in the cancellation of two journal packages, 70 individual journal subscriptions, and a selection of databases. Instead of picking up journal subscriptions proactively, the librarians elected to monitor interlibrary loan (ILL) demand for journals in the two packages. WCU faces additional collections budget cuts for FY21. In preparation, the authors set out to evaluate the previous collection review, identify any deficiencies in the process, and assess the impact of the cancellation decisions have had by 
looking at journal and database cancellations separately. This paper shows their findings
regarding ongoing demand for the cancelled journals and measuring cost savings achieved.

\section{Literature Review}

Published case studies on serials assessments typically follow a framework wherein the authors describe the environment or instigating factors for undergoing the assessment; the purported goals (i.e. a budget shortfall or other outcome of the project); the methodology, including the selected criteria; the data gathering process for both quantitative and qualitative measures; the results or final cancellation figures; and finally how the information is communicated with stakeholders. The discussion and conclusion may include the authors' reflection back on the process, the pain points felt, or mistakes to avoid. But even as collection assessment is framed as a cyclical process, there is a fragmented approach to closing the loop on assessment and how (or whether) the authors assess the effectiveness of the project.

A common method for assessing journal reviews is through analysis of interlibrary loan or document delivery requests post-cancellation. ILL is often promoted as the alternate solution to providing the cancelled journal content (for a recent example, see Blouin \& Westbrooks, 2020). Many studies have shown journal cancellations do not lead to a significant increase in ILL borrowing requests (Calvert et al., 2013; Pedersen et al., 2014 p. 247). Nabe \& Fowler (2015, p. 22), for instance, reported in the 5 years post-cancellation, the total number of ILL requests for 
Wiley titles was less than $10 \%$ of the number of downloads from the package prior to cancellation. Nevertheless, libraries look to ILL request data to measure continued user demand. Likewise, many review the cost by title of document delivery services to evaluate whether such services in lieu of subscriptions continue to "provide access by the most cost-effective means" (Murphy \& Buckley, 2018, p. 245).

Libraries considering whether to cancel Big Deals typically undergo a cost-benefit analysis to decide whether to proceed or to identify which Big Deal to cancel. Sjoberg's (2017) review of the literature on Big Deal cancellations succinctly identifies the factors and strategies libraries employ in their analyses, as well as the political and communication challenges to effectively cancelling one of these packages. Libraries may categorize titles in Big Deals into high- or low-use categories and compare the cost of the package to the individual subscription costs for high-use titles (Jones 2013, p.138; Glasser 2013, p. 272-273). Libraries that do cancel Big Deals typically report on the net savings of moving away from the package back to individual subscriptions (Jones 2013, p. 139; Nabe \& Fowler, 2015, p. 23).

\footnotetext{
Common thinking about Big Deals assumes high use will lead to high numbers of turnaways, which will translate into significant numbers of document delivery or ILL requests. Bucknell (2008, p. 198), when modelling how Big Deal cancellations would affect the University of Liverpool library, said "[a]fter four years we would have lost access to 8,600 journals, leading to 690,000 article turnaways per year. A proportion of these would lead to document delivery requests, incurring significant additional cost to the library, but in other cases users would 'make
} 
do' with other articles that they were able to Download." Published studies may conclude with the library deciding against cancellation of a Big Deal based on an analysis of use, choosing, instead, to renegotiate better terms with the publisher or find other ways to address budget shortfalls (Glasser, 2013, p. 273; Wolfe et al., 2009, p. 117).

Lastly, articles on serials cancellations include a short discussion on lessons learned, wherein the authors identify pain points in the process, provide a statement on whether the process was successful, or briefly reference faculty satisfaction with the process (Nixon, 2010, p. 310; Jones 2013, p. 139-140). These discussions tend to be brief, informal, and anecdotal.

\section{Background}

Since 2010, WCU has seen an $8 \%$ overall decrease in the collections budget. During this time, there were 5 years where the allocated budget remained flat. WCU librarians have relied on end of year money to help compensate for yearly increases to the serials budget but this money is not guaranteed and they have seen less of this money in recent years. Over this time the strategy for reviews of the collection has evolved. What started out as a project to identify "easy" resources to cut (e.g. duplicated formats, low use, etc.) to stay within the allotted budget has become a much more difficult task. Even with a permanent increase to the allocated budget in 2018, the library will need to move forward substantial cancellations in the coming year. 


\subsection{Targeting Journal Packages}

The library elected to go forward with the scenario that targeted a combination of high- and lowuse, niche and interdisciplinary resources. This scenario also included two of the lowestperforming journal packages, Cambridge and Emerald, for cancellation. Before committing these to the list of cancellations, the collections committee conducted an analysis on both packages.

- Package usage: analyzed the distribution of usage by title within the package, including the percent of titles in the package with high, moderate, and low use.

- Overlap: identified titles with access in other databases, the coverage dates and embargoes.

- Summary information: the package was looked at holistically. Metrics that were considered were percentage of titles in the package with alternate access, percentage with high use, and percentage with no use. 


\subsection{Negotiating Cuts}

After completing the data analysis, the next step was to decide how to select which titles to resubscribe to individually. In the end, it was decided not to proactively pick up any titles. The library had access to a majority of the high-use titles in each package through aggregator databases with a small embargo. An account was established with Get It Now and ILL staff were instructed to prioritize requests for journals with these publishers. To assuage concerns by subject liaisons, plans were put into place to monitor and periodically assess ILL requests for these titles and resubscribe if the cost of ILL requests approached the cost of a subscription. These steps were deemed an acceptable compromise for liaisons.

\subsection{Outcomes}

The library's collection review strategy needed to achieve several specific outcomes to be successful. The cancellations needed to:

1. Reduce subscription costs to balance the budget;

2. Minimize negative impact on the library's ability to meet the resource needs of academic programs;

3. Allow ongoing access to content cost-effectively through ILL and document delivery; and, 


\section{Methodology}

The data sources for this study were EBSCOnet for title lists, subscription cost information, and historical price information; III Sierra for past subscription price information; ILLiad and Tipasa for ILL requests and interlibrary loan fee management (IFM) costs; Copyright Clearance Center for Get It Now requests; journal vendor sites for COUNTER R4 JR2 reports; and local data sources for past journal package analysis and operational expenditures. SAS 9.4 was used to combine data sources and to perform some cost calculations.

\subsection{Post-cancellation ILL requests}


Lists of journals borrowed through ILL and filled between 2018 and 2019 came from two sources. For January 2018 through July 2019, the authors ran the most requested journals report from ILLiad where the number of requests were greater than zero. Data for August 2019 through December 2019 came from Tipasa using OCLC's borrower resource sharing stats report. To exclude canceled or unfilled requests in the Tipasa report, the data were limited to requests having a filled date. Using SAS, the authors ran SQL queries to match the list of cancelled journals to the ILL journal requests by ISSN. The report provided the total number of ILL requests by journal in the post-cancellation period.

\subsection{Post-cancellation costs}

Most important to the authors were the total actual costs incurred by the library for access to the previously subscribed content post-cancellation. These costs include Get It Now article fees, subscription costs for one resubscribed journal title, and the actual ILL costs over the postcancellation period. ILL costs included interlibrary loan fee management (IFM) transaction costs (\$0.25 per request), IFM library-to-library borrowing charges, and ILL overhead cost (\$13 per request). The ILL overhead cost for FY19 comprised

- Staff salaries, excluding fringe, for 1 FTE borrowing and 0.5 FTE lending;

- OCLC subscriptions for WorldShare ILL and ILLiad/Tipasa;

- Annual maintenance fee for the scanners; 
- All IFM fees;

- All royalties paid to the Copyright Clearance Center; and,

- All shipping costs for USPS and UPS (overestimated as non-ILL costs could not be excluded).

\begin{abstract}
The overhead cost-per-transaction utilized the total overhead cost divided by the number of borrowing, lending, and document delivery transactions for filled and unfilled requests.
\end{abstract}

\title{
4.3 Hypothetical cost projections
}

For comparison, the authors estimated what it would have cost to subscribe to these titles. First, the authors projected what the subscription costs would have been if the library had not cancelled any individual titles or packages. The amount was calculated by taking the subscription cost paid in Sierra and projecting annual price increases due to inflation. Individual journal subscription inflation rates were set by taking the average inflation rate per year from EBSCO's five-year price analysis by title report for titles on the library's -01 subaccount (individual subscriptions). The calculation was sensitive to when the cancellation took effect. For instance, the cumulative cost for a journal cancelled as of January 2018 started with the actual subscription cost from 2017, and comprised estimated subscription prices with inflation for 2018 and 2019. Cost estimates for journals cancelled effective 2019 would project from the actual subscription cost from 2018. 
The historical annual inflation rates for the Emerald and Cambridge journal packages were not consistent or fixed by the contract. The authors chose to substitute the average inflation rate per year from the EBSCO historical price analysis for all subaccounts. Table 1 shows the estimated inflation rates used in the study. The total cumulative, hypothetical costs were summed over the entire post-cancellation period.

[insert Table 1 here]

Table 1. Estimated inflation rates by purchase type.

Second, the authors estimated what it would have cost the library to subscribe to the journals instead of filling article requests. In this case, the authors used the 2020 subscription cost from EBSCOnet for titles with either an ILL or Get It Now request and projected the cost backwards using the same inflation rates in Table 1. For instance, the cumulative cost of a journal with a Get It Now request in 2018 would include the estimated 2018 and 2019 subscription costs. The cumulative, hypothetical costs for journals with article requests were summed over the post-cancellation period.

\subsection{Turnaway data}


Lastly, the authors investigate whether a correlation existed between the numbers of turnaways and ILL requests. Turnaway data came from COUNTER R4 JR2 reports for Emerald and Cambridge for 2018 and 2019. Individual journals were excluded to simplify data collection. Emerald data were only available through March 2019 when the publisher stopped providing COUNTER R4 data. The authors acknowledge turnaway data are incomplete for the journals included in this study.

\section{Results}

\subsection{Post-cancellation costs}

Over the two-year period following cancellations, Hunter Library filled 44 article requests filled through ILL and 2 article requests through Get It Now for cancelled titles. One individual journal subscription was added for a former Cambridge package title. The total expenses incurred for January 2018 through December 2019 were $\$ 2,837$.

\subsection{Cost projection comparisons}


The hypothetical cost projections for all cancelled titles and for cancelled titles with ILL and Get It Now requests are summarized in Table 2. Subscribing to journal titles individually would cost the library more than 1.7 times the price of maintaining package subscriptions.

\author{
[Insert Table 2 here] \\ Table 2. Estimated cumulative subscription costs for cancelled titles over the January 2018 - \\ December 2019 period.
}

\title{
5.3 Turnaways
}

In the analysis period, there were a total of 1,597 turnaways for package titles. $56 \%$ of all package titles had at least 1 turnaway. For package titles with ILL requests, 544 cumulative turnaways translated into 33 ILL requests. Figure 1 shows the relationship between number of turnaways and the number of ILL requests for a journal title. Even without rigorous statistical analysis, there does not appear to be a correlation between the number of turnaways and the number of ILL requests made.

[insert Figure 1 here]

Figure 1. Plot of turnaways versus the number of ILL requests for journal package titles. 


\section{Conclusions}

Post-cancellation costs totaled approximately $2 \%$ of what the library would have spent on cancellations. Additionally, the data show that even limiting individual subscriptions to titles with actual requests is not feasible as publishers price individual subscriptions at rates that libraries cannot afford. The publishers create a reality where libraries have no choice but to maintain journal packages to provide access to the content. For Emerald, in particular, there was at least one journal that cost nearly as much as the entire package. The takeaway is moving from a package to a core collection of highly used titles is a losing proposition for libraries; there is no way to disentangle from a package, reduce costs, and maintain significant subscription access to journals.

Based on the data, the authors feel confident that the decision to cancel these two journal packages has not adversely impacted ILL in terms of increased cost and usage. The data show that demand for journals has not met the threshold necessary to consider adding additional subscriptions. The data are likely strongly influenced by the continued access to the journals to the near present through aggregators. While the authors acknowledge it is unlikely all journal packages would result in the same outcome, they do feel more confident considering larger journal packages in future cancellation decisions. 


\section{Future Directions}


This paper focused on the author's assessment of providing access through ILL and document delivery to journal content that was cancelled in their last collection review and outlining their framework for monitoring the repercussions of cancelled journal packages. One of the outcomes not covered in this paper was ensuring that the library was still adequately meeting the resource needs of academic programs and minimizing negative impacts of cancellations. The authors are currently undertaking a study to learn about how their last collection review impacted the campus community. They are interested in determining if the cancelled databases have had a negative impact on the teaching, learning, and research needs of students, faculty, and staff and whether the process used for the collection review continues to provide information needed to make the best decision. 


\section{References}

Bucknell, T. (2008). Usage statistics for Big Deals: Supporting library decision-making. Learned Publishing, 21, 193-198. https://doi.org/10.1087/095315108X323893

Calvert, K., Fleming, R., \& Hill, K. (2013). Impact of journal cancellations on interlibrary loan demand. Serials Review, 39(3), 184-187. https://doi.org/10.1080/00987913.2013.10766391

Blouin, B., \& Westbrooks, E. (2020, April 9). Upcoming Elsevier cancellations. UNC University Libraries News. https://library.unc.edu/2020/04/upcoming-elsevier-cancellations/

Jaskowiak, M., \& Spires, T. (2018). Subscription alternations: Usages of canceled journal subscriptions via article delivery methods, Serials Review, 44(2), 98-103. https://doi.org/10.1080/00987913.2017.1396099

Jones, M. A., Marshall, D., \& Purtee, S. A.(2013). “Big Deal” deconstruction, The Serials Librarian, 64(1-4), 137-140. https://doi.org/10.1080/0361526X.2013.760389

Murphy, J. A., \& Buckly, C. E.. (2018). Document delivery as a supplement or replacement for serial subscriptions, Serials Review, 44(3), 241-246. https://doi.org/10.1080/00987913.2018.1525238

Nabe, J., \& Fowler, D. C. (2015). Leaving the 'Big Deal'... five years later, The Serials Librarian, 69, 20-28. https://doi.org/10.1080/0361526X.2015.1048037

Nixon, J. M. (2010). A reprise, or round three: Using a database management program as a decision-support system for the cancellation of serials, The Serials Librarian, 59, 302312. https://doi.org/10.1080/03615261003619086 
Pedersen, W. A., Arcand, J., \& Forbis, M. (2014) The Big Deal, interlibrary loan, and building the user-centered journal collection: A case study, Serials Review, 40(4), 242-250. https://doi.org/10.1080/00987913.2014.975650

Sjoberg, C. (2017). E-journals and the Big Deal: A review of the literature. SLIS Student Research Journal, 6(2). https://scholarworks.sjsu.edu/ischoolsrj/vol6/iss2/3/

Wolfe, D., Tafuri, N., Owen, N., Day, R., \& Lesher, M. (2009). Smoking out the Big Deal: Getting what you want without getting stung, The Serials Librarian, 56, 116-121. https://doi.org/10.1080/03615260802679291 


\begin{tabular}{|l|l|l|}
\hline & Individual Journals & Journal Packages \\
\hline FY2018 & 0.03 & 0.037 \\
\hline FY2019 & 0.042 & 0.033 \\
\hline
\end{tabular}

Table 1. Estimated inflation rates by purchase type. 


\begin{tabular}{|l|l|}
\hline & Projected 2-Year Subscription Costs \\
\hline All cancelled titles and packages & $\$ 153,487$ \\
\hline Cancelled titles with filled article requests & $\$ 263,780$ \\
\hline
\end{tabular}

Table 2. Estimated cumulative subscription costs for cancelled titles over the January 2018 December 2019 period. 


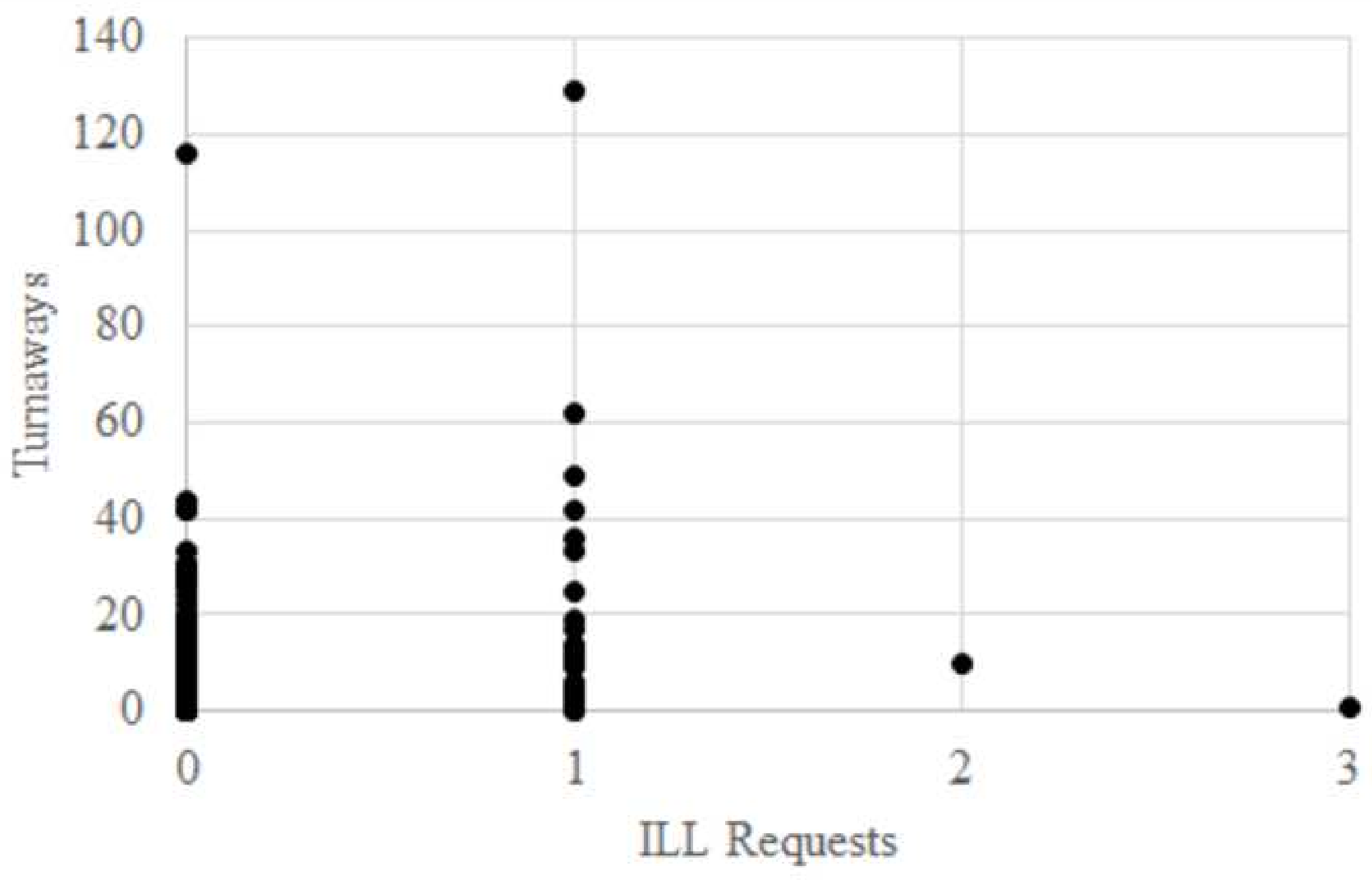

